OPEN ACCESS

Edited by:

Silvia Giordani,

Dublin City University, Ireland

Reviewed by:

Shudipto Konika Dishari, University of Nebraska-Lincoln,

United States

Simonetta Antonaroli,

University of Rome Tor Vergata, Italy

*Correspondence:

Ruilan Guo

rguo@nd.edu

Specialty section:

This article was submitted to Green and Sustainable Chemistry, a section of the journal

Frontiers in Chemistry

Received: 15 May 2020

Accepted: 29 June 2020

Published: 04 August 2020

Citation:

Wang T, Li T, Aboki J and Guo R (2020) Disulfonated Poly(arylene ether sulfone) Random Copolymers Containing Hierarchical Iptycene Units for Proton Exchange Membranes.

Front. Chem. 8:674

doi: 10.3389/fchem.2020.00674

\section{Disulfonated Poly(arylene ether sulfone) Random Copolymers Containing Hierarchical Iptycene Units for Proton Exchange Membranes}

\author{
Tao Wang, Tianyun Li, Joseph Aboki and Ruilan Guo* \\ Department of Chemical and Biomolecular Engineering, University of Notre Dame, Notre Dame, IN, United States
}

Two series of disulfonated iptycene-based poly(arylene ether sulfone) random copolymers, i.e., TRP-BP (triptycene-based) and PENT-BP (pentiptycene-based), were synthesized via condensation polymerization from disulfonated monomer and comonomers to prepare proton exchange membranes (PEMs) for potential applications in electrochemical devices such as fuel cell. To investigate the effect of iptycene units on membrane performance, these copolymers were systematically varied in composition (i.e., iptycene content) and the degree of sulfonation (i.e., 30-50\%), which were characterized comprehensively in terms of water uptake, swelling ratio, oxidative stability, thermal and mechanical properties, and proton conductivity at various temperatures. Comparing to copolymers without iptycene units, TRP-BP and PENT-BP ionomers showed greatly enhanced thermal and oxidative stabilities due to strong intra- and inter-molecular supramolecular interactions induced by hierarchical iptycene units. In addition, the introduction of iptycene units in general provides PEMs with exceptional dimensional stability of low volume swelling ratio at high water uptakes, which is ascribed to the supramolecularly interlocked structure as well as high fractional free volume of iptycene-based polymers. It is demonstrated that the combination of high proton conductivity and good membrane dimension stability is the result of the synergistic effects of multiple factors including free volume (iptycene content), sulfonation degree, hydrophobicity, and swelling behavior (supramolecular interactions).

Keywords: iptycene-containing poly(arylene ether sulfone), random copolymers, high free volume, proton exchange membrane, fuel cell

\section{INTRODUCTION}

With the increasing world population and limited fossil energy sources, clean, and sustainable energy has become a hot topic (Dincer, 2000; Omer, 2008; Chu and Majumdar, 2012). Fuel cells are regarded as promising energy devices for vehicle propulsion, stationary, and portable power with high energy conversion, decent energy density, and sustainability (Hickner et al., 2004; Smitha et al., 2005; Peighambardoust et al., 2010; Wang et al., 2011). Proton exchange membrane fuel cells (PEMFCs) using proton exchange membranes (PEMs) as solid electrolyte are widely studied for their high proton conductivity, good chemical, thermal, and mechanical stabilities. 
The state-of-the-art proton exchange membrane Nafion ${ }^{\circledR}$ produced by Dupont has dominated the commercial field for their exceptional chemical and mechanical stabilities as well as good conductivities, resulting from the poly(perfluorosulfonic acid) structure. However, the drawbacks of high cost, low operation temperature, poor conductivity at low relative humidity, and high fuel permeability promote the research for alternative non-fluorinated structures such as poly(arylene ether)s, poly(imide)s and poly(ether sulfone)s (Ghassemi and McGrath, 2004; Harrison et al., 2005; Liu et al., 2007; Miyatake et al., 2007; Matsumoto et al., 2008). Among the diverse structures reported in the literature, disulfonated poly(arylene ether sulfone) copolymers, such as BPSH series (Wang et al., 2002) are promising candidates for PEMFCs for their high proton conductivities with facile synthesis. Much efforts have been focused on modifying the membranes, including but not limited to introducing pendant groups (Wang et al., 2012; Zhao et al., 2013; Zhou et al., 2020), developing acid-base membranes (Yue et al., 2017; Ahn et al., 2018), preparing block copolymers (Lee et al., 2008; Li et al., 2012; Assumma et al., 2015), and blending sulfonated polysulfone with other polymers and fillers (Bi et al., 2010; Liang et al., 2013; Wang et al., 2019). Nevertheless, there is still a lot of room to improve for the polysulfone-based PEMs in terms of proton conductivities and dimensional stabilities to enable practical applications.

Recently, incorporating bulky, space-occupying (i.e., high free volume) moieties into ionic polymers has attracted a lot of attention for various membrane applications including PEMFCs. The main idea is to enable high water uptake via high fractional free volume to address the loss of water at low humidity and high temperature while suppressing excessive water swelling via highly rigid backbone structure. Zhang and his co-workers first introduced poly(arylene ether sulfone) random copolymers containing iptycene (i.e., triptycene and pentiptycene) with post-sulfonation treatment and reported reduced water swelling without loss of proton conductivities (Gong and Zhang, 2011; Gong et al., 2011). Swager group recently found that triptycene-based poly(ether ketone)s with increased fractional free volume showed enhanced proton conductivities under the conditions of low relative humidity and high temperature (Moh et al., 2018). They attributed the enhanced performance to the strong ability of retaining more water molecules and relieving the high internal energy enabled by high intrinsic free volume associated with bulky triptycene moieties in the polymer structures.

However, most existing studies of ionic polymers containing bulky structure units used post-polymerization sulfonation methods to introduce ionic groups (e.g., sulfonate) into polymer structures, where aromatic polymers were sulfonated by concentrated sulfuric acid, chlorosulfonic acid, fuming sulfuric acid, or sulfurtrioxide. Post-polymerization sulfonation in general is not able to attain precise control of the sulfonation degree and the location or distribution of ionic groups, and usually has low sulfonation efficiency. Moreover, post modifications are frequently accompanied with possible polymer backbone degradation and undesired side reactions due to the use of strong acidic media that result in deteriorated membrane properties (Hickner et al., 2004). For example, Genova-Dimitrova et al. (2001) reported that the use of strong sulfonating agent induced chain cleavage, as evidenced by the decreased viscosity upon post sulfonation. In this regard, preparing ion-containing polymers directly from disulfonated ionic monomers is beneficial in terms of better controlling the sulfonation degree and the location of sulfonate groups and achieving high molecular weight in resulting ionic polymers. Recently, we reported triptycene-containing poly(arylene ether sulfone) multiblock copolymers prepared directly from sulfonated monomers, which exhibit excellent dimensional stability with low swelling ratios despite of their relatively high water uptake (Aboki et al., 2018). We demonstrated that the supramolecular interlocking interactions and $\pi-\pi$ stacking associated with triptycene units in the hydrophobic blocks are instrumental in suppressing the undesired excessive water-swelling behavior frequently observed in common ionic membranes. The excellent properties of triptycene-containing PEMs and related ionic exchange membranes with high free volume motivate us to further explore the potential of high-freevolume ionic polymers, in particular, sulfonated poly(arylene ether sulfone)s for PEMFCs applications.

In this work, we report the use of iptycene-based (i.e., triptycene and pentiptycene) structure units and sulfonated monomer to prepare disulfonated poly(arylene ether sulfone) random copolymers with systematically varied composition and functionality. The extension to pentiptycene moieties, which has even bulkier structure and higher intrinsic internal free volume than triptycene ones (Luo et al., 2015), is expected to retain more water molecules and facilitate the proton conductivity at low relative humidity $(\mathrm{RH})$ and high temperature. Moreover, with more arene rings participating in strong supramolecular interactions and $\pi-\pi$ stacking, more rigid scaffolds are expected to form in pentiptycene-based structures that may further improve mechanical and dimensional stabilities. Specifically, two series of iptycene-containing, sulfonated polysulfone random copolymers are prepared via direct polycondensation reactions and comprehensively examined for PEMFC applications, including triptycene-based TRP-BP series and pentiptycene-based PENT-BP series with systematically varied iptycene content and sulfonation degree. Direct comparisons with non-iptycene-containing BPSH series are made to elucidate the effect of the incorporation of triptycene or pentiptycene moieties on PEM properties. Comprehensive investigations of physical properties, chemical structure, proton conductivity, and thermal, mechanical, and oxidative stabilities of these new iptycene-based sulfonated copolymers were conducted to establish the fundamental structure-property relationships for these new PEM materials, which would serve as a guide to new designs of high-performance PEMs.

\section{EXPERIMENTAL}

\section{Materials}

Triptycene-1,4-diol (TRP) (Wiegand et al., 2014) and pentiptycene-6,13-diol (PENT) (Luo et al., 2015) were synthesized according to previous literature. Anthracene, 
sodium hydrosulfite, 4,4'-dichlorodiphenylsulfone (DCDPS), and $4,4^{\prime}$-difluorodiphenylsulfone (DFDPS) were purchased from Alfa Aesar and used as received. 1,4-benzoquinone, tetrachloro-1,4-benzoquinone, potassium carbonate $\left(\mathrm{K}_{2} \mathrm{CO}_{3}\right)$, sodium bicarbonate, acetic acid, methanol, and 2-propanol were purchased from Sigma-Aldrich. 4,4'-biphenol (BP) and 3,3'-disulfonated-4,4'-dichlorodiphenylsulfone (SDCDPS) were purchased from Akron Polymer Systems and dried in vacuum at $110^{\circ} \mathrm{C}$ for $24 \mathrm{~h}$ before use. Anhydrous $\mathrm{N}, \mathrm{N}$-dimethylacetamide (DMAc), toluene, and hydrogen peroxide (30 wt\% solution) were purchased from EMD Millipore and used as received.

\section{Synthesis of Disulfonated Iptycene-Containing Poly(Arylene Ether Sulfone) Copolymers \\ Triptycene-Containing Copolymers}

A series of triptycene-containing disulfonated poly(arylene ether sulfone) random copolymers (i.e., TRP-BP series) with different molar ratios of TRP to $\mathrm{BP}$ and varied degrees of sulfonation were synthesized via nucleophilic polycondensation according to reported method (Scheme 1) (Luo et al., 2018). The nomenclature used for the copolymers is TRP-BP a:b-X, where $a: b$ is the TRP:BP molar ratio and $X$ is the molar percentage of sulfonated SDCDPS relative to non-sulfonated DCDPS in the copolymers, as shown in Scheme 1. For example, TRP-BP 1:1-35 refers to the copolymer containing 1:1 molar ratio of TRP:BP, $35 \mathrm{~mol} \%$ sulfonated monomer (SDCDPS), and $65 \mathrm{~mol} \%$ nonsulfonated monomer (DCDPS). It should be noted that random copolymers with high TRP molar contents (>66 mol\%) and high degree of sulfonation (>50 mol\%) did not have sufficiently high molecular weight for film formation due to the low reactivity between TRP and SDCDPS. A sample polymerization of TRP-BP 1:1-35 is as follows: $1.8621 \mathrm{~g}(10.0 \mathrm{mmol})$ of $\mathrm{BP}, 2.8633 \mathrm{~g}(10.0$ $\mathrm{mmol})$ of TRP, $3.4386 \mathrm{~g}(7.0 \mathrm{mmol})$ of SDCDPS, $3.7330 \mathrm{~g}(13.0$ $\mathrm{mmol})$ of DCDPS, and $3.3169 \mathrm{~g}(24.0 \mathrm{mmol})$ of anhydrous $\mathrm{K}_{2} \mathrm{CO}_{3}$ were charged into a three-necked round-bottom flask equipped with a condenser, mechanical stirrer, Dean-Stark trap, and nitrogen inlet. Anhydrous DMAc $(60 \mathrm{~mL})$ and toluene $(30 \mathrm{~mL})$ were then added to the flask, and the reaction was heated, under a $\mathrm{N}_{2}$ purge, to $145^{\circ} \mathrm{C}$ while stirring. The reaction was refluxed at $145^{\circ} \mathrm{C}$ for $4 \mathrm{~h}$ to azeotropically dehydrate the system. Afterward, toluene was removed from the reaction by slowly increasing the temperature to $185^{\circ} \mathrm{C}$. The reaction was allowed to proceed at $185^{\circ} \mathrm{C}$ for another $72 \mathrm{~h}$ until a viscous solution formed. The polymer solution was then cooled to room temperature, vacuum filtered to remove salts, and coagulated in a stirred 2-propanol bath. The precipitated fibrous TRP-BP copolymer was collected and dried under vacuum at $120^{\circ} \mathrm{C}$ for $24 \mathrm{~h}$.

\section{Pentiptycene-Containing Copolymers}

Similar procedures were taken to synthesize pentiptycenecontaining disulfonated polysulfone random copolymer series, i.e., PENT-BP series, with varied pentiptycene content and degree of sulfonation. The same naming system is applied to the PENTBP series. A typical synthesis of PENT-BP 1:2-40 (1:2 refers to the molar ratio of PENT:BP and 40 is the sulfonation degree of the copolymer) is described as follows: $2.3127 \mathrm{~g}$ PENT ( $5 \mathrm{mmol}$ ), $1.8621 \mathrm{~g}$ BP (10 mmol), $2.9474 \mathrm{~g}$ SDCDPS (6 mmol), $2.2883 \mathrm{~g}$ DFDPS $(9 \mathrm{mmol})$ and $4.1462 \mathrm{~g} \mathrm{~K}_{2} \mathrm{CO}_{3}(30 \mathrm{mmol})$ were charged into a $100 \mathrm{~mL}$ three-neck flask with a nitrogen inlet, a mechanical stirrer, and a Dean-Stark trap. Then $50 \mathrm{~mL}$ anhydrous DMAc and $25 \mathrm{~mL}$ toluene were added and the reaction mixture was refluxed at $145^{\circ} \mathrm{C}$ for $4 \mathrm{~h}$ to azeotropically dehydrate the system. While removing the toluene, the temperature was slowly increased to $185^{\circ} \mathrm{C}$ and hold for $72 \mathrm{~h}$. The resulting viscous polymer solution was filtered to remove salts and then precipitated in methanol with stirring. The fibrous copolymer was then collected and dried in vacuum oven for $24 \mathrm{~h}$ at $120^{\circ} \mathrm{C}$.

As a control for comparisons to investigate the effect of iptycene structure, a series of non-iptycene-containing BPSH random copolymers with controlled degree of sulfonation were also synthesized from BP, DCDPS, and SDCDPS according to previous reports (Wang et al., 2001, 2002).

\section{Film Preparation and Acidification}

All salt-form (as synthesized) copolymer films were prepared via a solution casting method. In a typical case, the salt-form copolymers were dissolved in DMAc to form a $\sim 7 \% \mathrm{w} / \mathrm{v}$ solution, which was filtered through $0.45 \mu \mathrm{m}$ Teflon ${ }^{\circledR}$ syringe filters. The filtered solutions were cast onto clean, leveled glass plates and dried under an infrared lamp at $\sim 55^{\circ} \mathrm{C}$ for $24 \mathrm{~h}$ to form polymer films. The residual solvent was further removed by drying the film under vacuum at $120^{\circ} \mathrm{C}$ for $24 \mathrm{~h}$.

The as-cast salt-form thin films were converted to acid formthat is, $\mathrm{K}^{+}$was replaced with $\mathrm{H}^{+}$in the copolymer structure shown in Scheme 1-by boiling the films in $0.5 \mathrm{M}$ sulfuric acid solution for $2 \mathrm{~h}$ followed by boiling the films in deionized (DI) water for another $2 \mathrm{~h}$ (Kim et al., 2004). All obtained acid-form polymer films with thickness between 30 and $70 \mu \mathrm{m}$ were stored in DI water until use.

\section{Characterization of Polymers and Films}

Intrinsic viscosity (IV) of salt-form copolymers was determined in $0.05 \mathrm{M} \mathrm{LiBr-NMP}$ solution at $25^{\circ} \mathrm{C}$ using a CannonUbbelohde viscometer and the average value of at least three measurements was reported. The density of dry acid-form membrane was measured using a density measurement kit (ML-DNY-43, Mettler Toledo) and an analytical balance (ML204, Metter Toledo) at room temperature. The dry membrane density $\rho_{d r y}$, was determined according to Archimedes' principle as follows:

$$
\rho_{d r y}=\frac{m_{\text {air }}}{m_{\text {air }}-m_{\text {wet }}}\left(\rho_{\text {aux }}-\rho_{\text {air }}\right)
$$

where $m_{\text {air }}$ is the membrane weight measured in air and $m_{\text {wet }}$ is measured in cyclohexane. The density of cyclohexane $\rho_{a u x}$ was determined at measured temperature and $\rho_{\text {air }}$ was taken as 0.0012 $\mathrm{g} / \mathrm{cm}^{3}$ (Luo et al., 2018).

The thermal stability (weight loss) of the acid-form membranes was evaluated by thermogravimetric analysis (TGA) using a TA instrument Q500. The samples were heated 


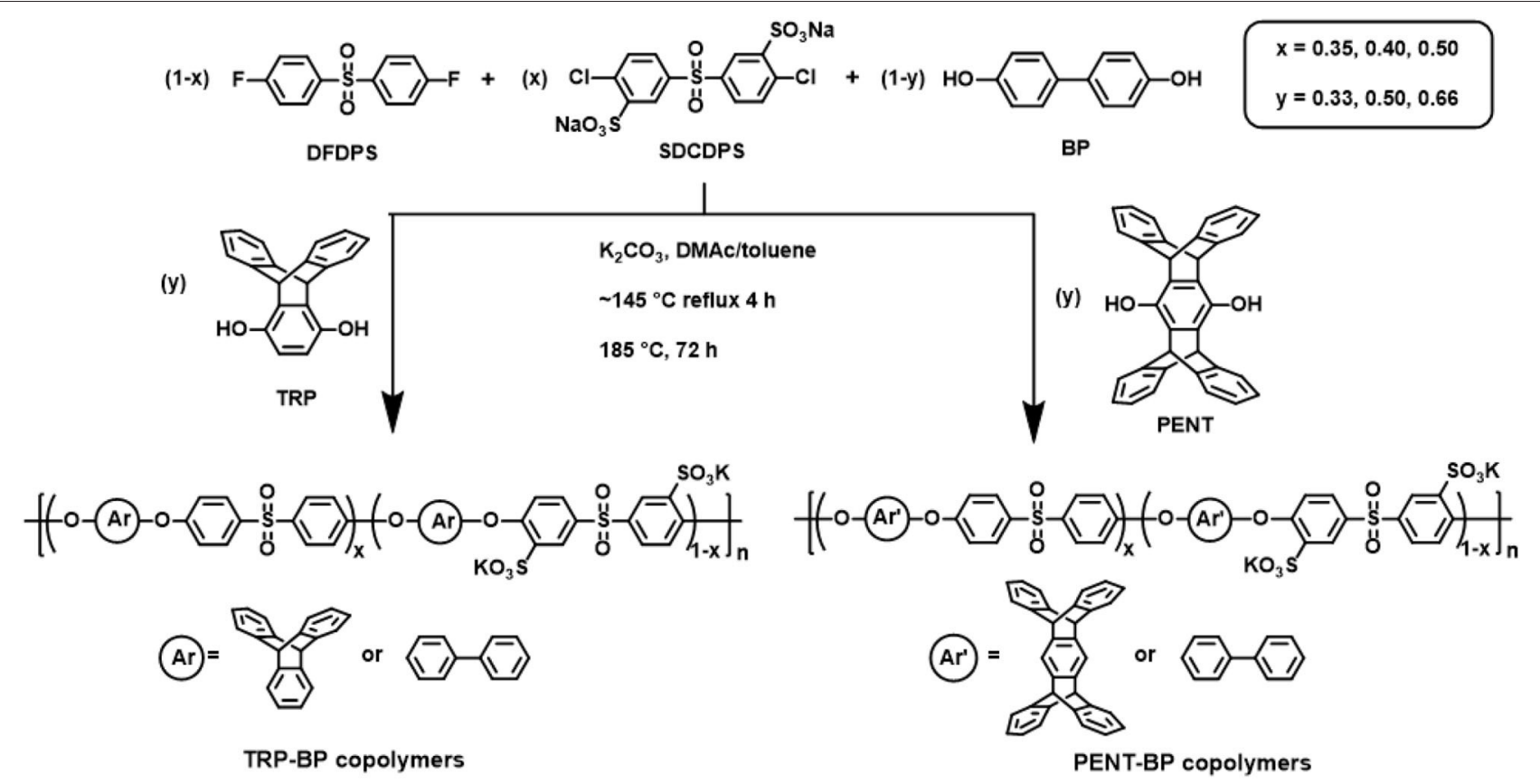

SCHEME 1 | Synthesis of TRP-BP and PENT-BP disulfonated random copolymers with controlled composition.

from 50 to $800^{\circ} \mathrm{C}$ at a heating rate of $10^{\circ} \mathrm{C} / \mathrm{min}$ under $\mathrm{N}_{2}$ atmosphere after drying at $150^{\circ} \mathrm{C}$ for $30 \mathrm{~min}$ in the TGA furnace. The differential scanning calorimetry (DSC) analyses were done on a TA instrument Q2000 with liquid nitrogen cooling system at a heating rate of $10^{\circ} \mathrm{C} / \mathrm{min}$. Prior to the measurement, membranes were dried under vacuum at $120^{\circ} \mathrm{C}$ for $24 \mathrm{~h}$ to fully remove residual solvents. The samples were tested within the range of $50-325^{\circ} \mathrm{C}$ and the glass transition temperature $\left(T_{g}\right)$ was obtained from the second heating cycle (Aboki et al., 2018).

Membrane oxidative stability was tested by immersing the films in hot Fenton's reagent $\left(3 \% \mathrm{H}_{2} \mathrm{O}_{2}\right.$ aqueous solution containing $2 \mathrm{ppm} \mathrm{FeSO}_{4}$ ) at $80^{\circ} \mathrm{C}$ for $1 \mathrm{~h}$. Then the residual weight $(R W)$ was measured after drying the remaining film in vacuum oven at $100^{\circ} \mathrm{C}$ overnight.

The dry-weight ion exchange capacity $\left(\mathrm{IEC}_{\mathrm{W}}, \mathrm{meq} / \mathrm{g}\right)$ (Hickner et al., 2004) of all acid-form membranes was determined by acid-base titration method. Dry membranes were immersed in $5 \mathrm{M} \mathrm{NaCl}$ solution for $48 \mathrm{~h}$ to release the $\mathrm{H}^{+}$. Then the solution was titrated by $0.01 \mathrm{M} \mathrm{NaOH}$ solution using phenolphthalein as indicator. The dry-weight-based $\mathrm{IEC}_{\mathrm{w}}$ was calculated as follows,

$$
\operatorname{IEC}_{w}(m e q / g)=\frac{c_{\mathrm{NaOH}} \times V_{\mathrm{NaOH}}}{m}
$$

where $c_{\mathrm{NaOH}}$ and $V_{\mathrm{NaOH}}$ are the concentration and the used volume of $\mathrm{NaOH}$ solution, respectively, and $m$ is the mass of the sample. Average values of IEC $_{\mathrm{W}}$ were obtained and reported from at least 3 samples for each film.

Mechanical properties of the acid-form films were determined via uniaxial tensile testing with a Bose Electro-Force 3300 instrument with $25 \mathrm{lb}$ load cell at $25^{\circ} \mathrm{C}$ following our previous method (Aboki et al., 2018). The hydrated specimens were prepared as dumbbell shape specimens of $25 \times 10 \mathrm{~mm}$ (total) and $10 \times 5 \mathrm{~mm}$ (test area). The stress-strain curve was obtained at a stretching rate of $2 \mathrm{~mm} / \mathrm{min}$. At least three samples were tested for each copolymer and the average value was reported.

Water uptake (WU) of acid-form membranes was evaluated by immersing fully dried polymer films $\left(W_{d r y}\right)$ in DI water at room temperature for $24 \mathrm{~h}$. The membranes were wiped using Kimwipe $^{\circledR}$ to remove any surface water and quickly weighed $\left(W_{\text {wet }}\right)$. WU in weight percent was calculated as follows:

$$
W U(w t \%)=\frac{W_{w e t}-W_{d r y}}{W_{d r y}} \times 100 \%
$$

Swelling ratio (SR) of the membranes was determined by measuring the volume change after immersing the films in DI water. The acid-form membranes were cut into rectangular shape and immersed in DI water at room temperature for $24 \mathrm{~h}$. The dimension (i.e., length, width, and thickness) of the films were measured before and after water immersion to calculate the dry and wet volume of the films. Then the $S R$ was calculated by the following equation:

$$
S R(\%)=\frac{V_{w e t}-V_{d r y}}{V_{d r y}} \times 100 \%
$$

To account for membrane swelling, the wet volume-based IEC values were also calculated from the weight-based $\mathrm{IEC}_{\mathrm{W}}$, density and swelling ratio as follows, 


$$
I E C_{v}(w e t)\left(m e q / \mathrm{cm}^{3}\right)=\frac{I E C_{w} \times \rho}{(1+S R)}
$$

where $I E C_{w}$, density and swelling ratio (SR) are all from experimentally determined values.

\section{Proton Conductivity Measurement}

The proton conductivity of the acid-form films under fully hydrated condition was measured in DI water on a PARSTAT $^{\circledR}$ MC 1,000 impedance spectrometer via Linear Sweep Voltammeter (LSV) using a 4-electrode BekkTech Conductivity Clamp BT-110. All the samples were cut into stripes $(30 \times 5 \mathrm{~mm})$. The conductivities of acid-form membranes were measured in DI water at varied temperatures ranging from 25 to $80^{\circ} \mathrm{C}$. The films were immersed in water for at least $10 \mathrm{~min}$ to obtain consistent resistance at each temperature. The resistance of sample was acquired from the slope of a linear voltage-current plot $(0.3-0.8 \mathrm{~V})$. The proton conductivity $\sigma$ $(\mathrm{S} / \mathrm{cm})$ was calculated as follows:

$$
\sigma=\frac{l}{R \times W \times T}
$$

where ohmic resistance $(R)$ was calculated from the slope of potential-current plot, $l$ is the distance between platinum wires $(0.425 \mathrm{~cm}), W$ and $T$ are the width and thickness of the membrane, respectively. The average value was recorded from at least 3 samples of each membrane.

\section{RESULTS AND DISCUSSION}

\section{Copolymer Synthesis and Characterization}

The synthetic route for iptycene-containing sulfonated copolymers is shown in Scheme 1 via condensation polymerization following nucleophilic aromatic substitution $\left(\mathrm{S}_{\mathrm{N}} \mathrm{Ar}\right)$ mechanism. Two structure parameters were adjusted in these two series of copolymers: the degree of sulfonation (ranging from 35 to 50\%) and the molar content of iptycene unit (ranging from 33 to 66\%). This has allowed systematic investigation of the structure-property relationship for these new iptycene-containing sulfonated polysulfones to elucidate the effect of iptycene structure on membrane properties. It should be noted that the molar content of TRP or PENT in the copolymers was limited due to the relatively low reactivity between TRP/PENT and SDCDPS as well as the low solubility of pentiptycene-based polymers, which prevented the formation of polymers with sufficiently high molecular weight for film casting. The chemical structures and the composition of iptycene-containing disulfonated copolymers were confirmed by ${ }^{1} \mathrm{H}$ NMR spectroscopy. Figure $\mathbf{S 1}$ shows representative ${ }^{1} \mathrm{H}$ NMR spectrum of a triptycene-based copolymer and a pentiptycene-based copolymer with peak assignment according to their structures. The actual molar contents of iptycene units in the copolymers were determined by the peak integration ratio of the iptycene moieties and the $\mathrm{BP}$ unit. The results matched the
TABLE 1 | Density, intrinsic viscosity (IV), decomposition temperature $\left(T_{d, 5 \%}\right)$, and

\begin{tabular}{|c|c|c|c|c|}
\hline Copolymers & Density $\left(\mathrm{g} / \mathrm{cm}^{3}\right)$ & $I V(d L / g)^{a}$ & $T_{d, 5 \%}\left({ }^{\circ} \mathbf{C}\right)^{\mathrm{b}}$ & $T_{g}\left({ }^{\circ} \mathrm{C}\right)^{\mathrm{C}}$ \\
\hline TRP-BP 1:1-35 & $1.41 \pm 0.04$ & $0.48 \pm 0.01$ & 383 & 254 \\
\hline TRP-BP 2:1-35 & $1.37 \pm 0.06$ & $0.54 \pm 0.01$ & 355 & 277 \\
\hline TRP-BP 1:2-40 & $1.33 \pm 0.01$ & $0.70 \pm 0.01$ & 392 & 281 \\
\hline TRP-BP 1:1-40 & $1.37 \pm 0.01$ & $0.52 \pm 0.01$ & 404 & 280 \\
\hline TRP-BP 1:2-50 & $1.38 \pm 0.01$ & $0.52 \pm 0.01$ & 382 & 280 \\
\hline TRP-BP 1:1-50 & $1.39 \pm 0.02$ & $0.42 \pm 0.01$ & 388 & 291 \\
\hline PENT-BP 1:2-40 & $1.33 \pm 0.01$ & $0.62 \pm 0.01$ & 427 & 296 \\
\hline PENT-BP 1:1-40 & $1.31 \pm 0.01$ & $0.75 \pm 0.01$ & 394 & 299, 311 \\
\hline PENT-BP 1:2-50 & $1.32 \pm 0.02$ & $0.50 \pm 0.01$ & 392 & 309 \\
\hline BPSH 30 & $1.37 \pm 0.02$ & $0.82 \pm 0.01$ & 352 & 248 \\
\hline BPSH 40 & $1.42 \pm 0.03$ & $1.16 \pm 0.01$ & 382 & 260 \\
\hline BPSH 50 & $1.40 \pm 0.01$ & $0.62 \pm 0.01$ & 341 & 271 \\
\hline
\end{tabular}
glass transition temperature $\left(T_{g}\right)$ of iptycene-containing polysulfone copolymers.

${ }^{a}$ Measured on salt-form samples in $0.05 \mathrm{M} \mathrm{LiBr} \mathrm{NMP} \mathrm{solution} \mathrm{at} 25^{\circ} \mathrm{C}$.

${ }^{b} 5 \%$ weight-loss temperature measured on acid-form samples under $\mathrm{N}_{2}$ atmosphere. ${ }^{c}$ Measured on acid-form samples by DSC at $10^{\circ} \mathrm{C} / \mathrm{min}, \mathrm{N}_{2}$.

target values, indicating successful synthesis of both copolymer series with well-controlled compositions. The intrinsic viscosity values of iptycene-containing copolymers are mostly in the range of $0.50 \sim 0.75 \mathrm{dL} / \mathrm{g}$ (Table 1 ), indicating sufficiently high molecular weight for film casting as shown later. The relatively lower IV values of TRP/PENT-BP series compared to the BPSH series indicating lower molecular weight than BPSH series due to lower reactivity of TRP and PENT series caused by the steric hindrance and poor solubility.

As shown in Table 1, at given degree of sulfonation, the dry membrane densities of iptycene-containing copolymers, both TRP-BP series and PENT-BP series were all lower than $\mathrm{BPSH}$ series without iptycene moieties. It seems to suggest that incorporating iptycene-based structure units might effectively disrupt the chain packing generating larger fractional free volume. Additional analysis reveals that the PENT-BP series exhibit lower densities than TRP-BP series at equivalent sulfonation degree (except TRP-BP 1:2-40). This observation could be rationalized by the larger free volume cavities than those of triptycene units, in particular, the internal free volume defined by the clefts between the benzene "blades" of pentiptycene units (Luo et al., 2015).

\section{Thermal Analysis and Mechanical Properties}

The thermal stability of the acid-form copolymer membranes was studied by thermogravimetric analysis (TGA) in nitrogen flow and the results of $5 \%$ weight-loss temperature $\left(\mathrm{T}_{\mathrm{d}, 5 \%}\right)$ are listed in Table 1. All the membranes showed a typical twostep degradation behavior (Figure 1). The first stage weight loss around $350^{\circ} \mathrm{C}$ was due to the loss of $-\mathrm{SO}_{3} \mathrm{H}$ group (Gong and Zhang, 2011). As such, copolymers with higher degree of sulfonation usually show lower thermal stability. The second stage loss above $500^{\circ} \mathrm{C}$ was ascribed to the degradation of the polymer main chains. All of the tested polysulfones show $T_{d, 5 \%}$ 

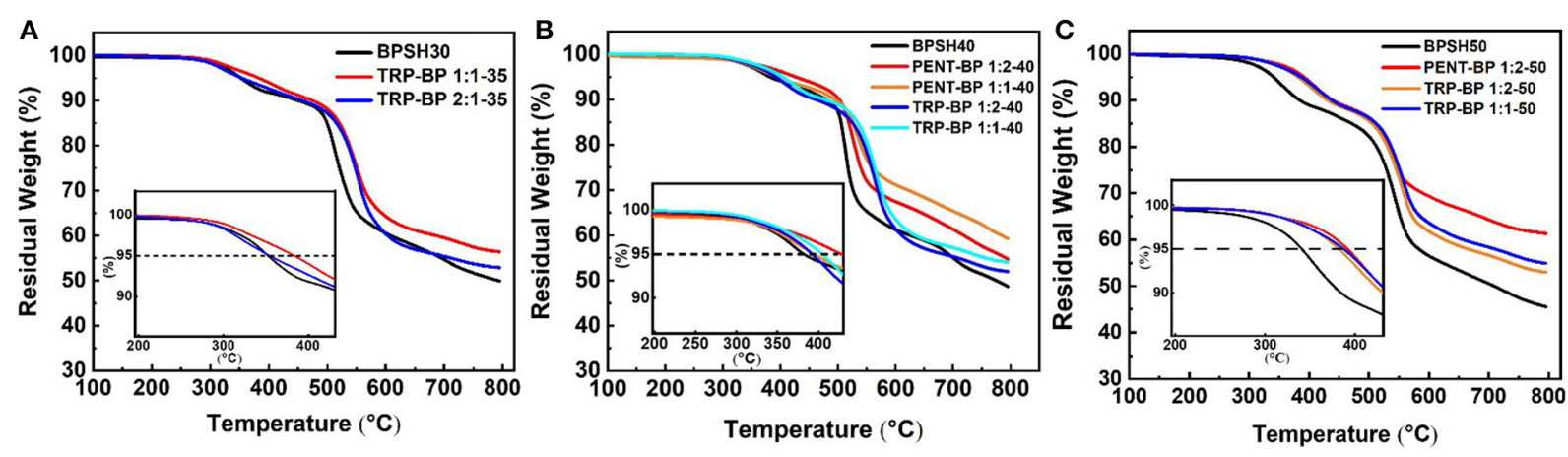

FIGURE 1 | The TGA curves of disulfonated copolymers at comparable sulfonation degrees.

higher than $300^{\circ} \mathrm{C}$, indicating sufficient thermal stability for use in PEMFCs. As a general observation, incorporation of iptycene moieties into the backbone appeared to improve the thermal stability of the copolymers given the same degree of sulfonation, which could be ascribed to the high rigidity of iptycene-based polymer structures and strong intermolecular and intramolecular $\pi-\pi$ interactions. For example, at the same degree of sulfonation of $50 \%$ (Figure 1C), BPSH 50 has a $T_{d, 5 \%}$ value of $341^{\circ} \mathrm{C}$, which is significantly lower than the iptycene-containing copolymers, i.e., PENT-BP 1:2-50 $\left(392^{\circ} \mathrm{C}\right)$, TRP-BP 1:2-50 $\left(382^{\circ} \mathrm{C}\right)$, and PENT-BP $1: 2-50\left(388^{\circ} \mathrm{C}\right)$. The same trend is observed when comparing the copolymers with similar IEC $_{\mathrm{W}}$ values. For example, PENTBP 1:1-40 (1.27 meq/g) and TRP-BP 1:1-35 (1.27 meq/g) showed $T_{d, 5 \%}$ values of 394 and $383^{\circ} \mathrm{C}$, respectively, which are much higher than $352^{\circ} \mathrm{C}$ of BPSH 30 (1.25 meq/g).

The glass transition temperatures were determined using TA Q2000 and the results are shown in Table 1. It can be seen that within the same copolymer series, $T_{g}$ increases with increasing the degree of sulfonation. This could be attributed to the fact that higher degree of sulfonation induces stronger intermolecular interactions by ionic effect that stiffens polymer backbone. As expected, iptycene-based sulfonated polysulfones show higher $T_{g}$ than BPSH series at the equivalent sulfonation degree. For example, the $T_{g}$ of TRP-BP 1:1(2)-40 and PENTBP 1:1(2)-40 increased by $\sim 8$ and $15 \%$, respectively, compared to $\mathrm{BPSH} 40$. The observed increase in $T_{g}$ suggests that the bulky and shape-persistent structures of iptycene units effectively increase the polymer chain rigidity. On the other hand, the strong intermolecular and intramolecular $\pi-\pi$ interactions between the benzene rings of iptycene units might also contribute to higher glass transition temperatures. This may also explains that PENT-BP series with more fused arene rings exhibit higher $T_{g}$ than TRP-BP copolymers at similar sulfonation degree. While previous studies reported that two $T_{g}$ 's might be observed for BPSH 50 and BPSH 60 (Wang et al., 2002), here we were able to observe only one $T_{g}$ for BPSH 50 and other copolymers at $50 \%$ sulfonation degree. It should be noted that the degradation of $-\mathrm{SO}_{3} \mathrm{H}$ group starts at $\sim 250^{\circ} \mathrm{C}$ (Figure 1), which may also obscure the $T_{g}$ detection. Interestingly, two distinct $T_{g}$ 's (299 and $311^{\circ} \mathrm{C}$ ) were detected for PENT-BP 1:1-40 (Figure S2), which correspond to the $T_{g}$ of the polymer matrix and ionic clusters, respectively. The unusual phenomenon here might be rationalized by the lower sulfonation degree and excellent thermal stability $\left(T_{d, 5 \%}=394^{\circ} \mathrm{C}\right)$ of PENT-BP 1:1-40.

Mechanical properties of membranes were tested on the acid-form films in fully hydrated state at room temperature. Depending on the degree of sulfonation and the content of iptycene units, the copolymer membranes showed tensile strength in a range of 16-48 MPa, Young's modulus of 0.11-0.48 $\mathrm{GPa}$, and elongation at break of 19-75\% (Table S1). While other factors, such as molecular weight, may have strong impact on mechanical properties, the iptycene-containing copolymers, especially the pentiptycene series, seem to be stiffer (higher Young's modulus) but less ductile (smaller elongation at break) than the non-iptycene-containing BPSH series due to much higher chain rigidity (higher $T_{g}$ ) upon the incorporation of iptycene units.

\section{Ion Exchange Capacity, Water Uptake, and Swelling Ratio}

Ion exchange capacity $\left(\right.$ IEC $\left._{\mathrm{w}}, \mathrm{meq} / \mathrm{g}\right)$ is an important factor for the PEM performance: high $\mathrm{IEC}_{\mathrm{W}}$ leads to high water uptake facilitating the proton transport; however, excessive water uptake causes severe dimensional instability and ion dilution, weakening the mechanical strength and reducing proton conductivity. To achieve high PEMFC performance, it is desirable to optimize the IEC $_{\mathrm{W}}$ by tuning the polymer composition to balance mechanical integrity and proton conductivity. The dry-weight IEC $_{\mathrm{w}}$ was obtained from the acid-base titration method using phenolphthalein as indicator, and the results were in agreement with the theoretical values calculated from the monomer feed ratio during polymerization (Table 2 ). The $0.1 \sim 0.2 \mathrm{meq} / \mathrm{g}$ deviation between calculations and titration results probably came from incomplete ion exchange and experimental errors. As expected, increasing the degree of sulfonation led to increases in $\mathrm{IEC}_{\mathrm{W}}$ values in all three copolymer series. Given the same degree of sulfonation, iptycene-containing copolymers have lower $\mathrm{IEC}_{\mathrm{W}}$ values than the BPSH series. This is due to higher molecular weight of repeat units in the iptycene series.

The water uptake and swelling behavior results are depicted in Figure 2. It is noted that there are multiple interplaying factors that regulate the water uptake and swelling behavior of the 
TABLE 2 | lon exchange capacity (IEC), water uptake (WU), and swelling ratio (SR).

\begin{tabular}{|c|c|c|c|c|c|}
\hline Copolymers & $\begin{array}{l}\text { IEC }_{\mathrm{w}}^{\mathrm{Cal}, \mathrm{a}} \\
\text { (meq/g) }\end{array}$ & $\begin{array}{l}\text { IEC }_{w}^{M e a, b} \\
(\mathrm{meq} / \mathrm{g})\end{array}$ & $\begin{array}{l}\text { IEC }_{v}(\text { wet })^{\mathrm{C}} \\
\left(\mathrm{meq} / \mathrm{cm}^{3}\right)\end{array}$ & WU (\%) & SR (\%) \\
\hline TRP-BP 1:1-35 & 1.38 & $1.27 \pm 0.01$ & $1.36 \pm 0.07$ & $65 \pm 4$ & $32 \pm 5$ \\
\hline TRP-BP 2:1-35 & 1.34 & $1.23 \pm 0.01$ & $1.35 \pm 0.07$ & $64 \pm 3$ & $25 \pm 4$ \\
\hline TRP-BP 1:2-40 & 1.61 & $1.46 \pm 0.01$ & $1.22 \pm 0.06$ & $67 \pm 3$ & $59 \pm 7$ \\
\hline TRP-BP 1:1-40 & 1.55 & $1.43 \pm 0.01$ & $1.33 \pm 0.08$ & $70 \pm 6$ & $47 \pm 9$ \\
\hline TRP-BP 1:2-50 & 1.92 & $1.76 \pm 0.02$ & $0.73 \pm 0.07$ & $155 \pm 5$ & $231 \pm 33$ \\
\hline TRP-BP 1:1-50 & 1.88 & $1.70 \pm 0.02$ & $0.63 \pm 0.04$ & $258 \pm 12$ & $274 \pm 23$ \\
\hline PENT-BP 1:2-40 & 1.44 & $1.35 \pm 0.01$ & $1.55 \pm 0.08$ & $31 \pm 4$ & $16 \pm 5$ \\
\hline PENT-BP 1:1-40 & 1.36 & $1.27 \pm 0.01$ & $1.49 \pm 0.06$ & $28 \pm 5$ & $12 \pm 4$ \\
\hline PENT-BP 1:2-50 & 1.75 & $1.60 \pm 0.01$ & $1.29 \pm 0.13$ & $99 \pm 17$ & $61 \pm 16$ \\
\hline BPSH 30 & 1.34 & $1.25 \pm 0.01$ & $1.53 \pm 0.05$ & $24 \pm 3$ & $12 \pm 3$ \\
\hline BPSH 40 & 1.72 & $1.59 \pm 0.02$ & $1.54 \pm 0.06$ & $44 \pm 2$ & $47 \pm 4$ \\
\hline BPSH 50 & 2.0 & $1.96 \pm 0.02$ & $1.41 \pm 0.07$ & $115 \pm 20$ & $95 \pm 10$ \\
\hline
\end{tabular}

${ }^{a}$ Calculated from monomer feed ratio during polymerization.

${ }^{b}$ Determined from titration method using $0.01 \mathrm{M} \mathrm{NaOH}$ solution.

${ }^{c}$ Calculated from Equation (5).

copolymer membranes, including $\mathrm{IEC}_{\mathrm{w}}$, fractional free volume, hydrophobicity, and intra- and intermolecular interactions like $\pi-\pi$ stacking. For all three copolymer series, a general trend is observed as expected that: higher $\mathrm{IEC}_{\mathrm{W}}$ or sulfonation degree yields higher water uptake and swelling ratio. Another general observation (with few exceptions as explained below) is that with similar $\mathrm{IEC}_{\mathrm{w}}$ or degree of sulfonation, iptycene-containing series seem to have larger water uptake (due to larger fractional free volume) but less volume swelling (possibly due to strong supramolecular interactions) than BPSH series. For example, comparing to BPSH 30 and BPSH 40, TRP-BP 1(2):1-35 and TRPBP 1:1(2)-40 copolymers with similar or even lower IEC showed much higher water uptake while maintaining dimensional stabilities (Figures 2A,B). Usually water uptake is proportional to free volume according to Yasuda's theory (Yasuda et al., 1969). The increased water uptake suggests that incorporation of bulky triptycene units increases the free volume compared to BPSH series. While the absolute values of swelling ratios for TRPBP series are higher than those of BPSH series at 35 and $40 \%$ sulfonation degrees, TRP-BP series are still deemed to have better dimensional stability considering their much higher water uptake than BPSH series. For example, comparing BPSH 40 and TRP-BP 1:1-40 copolymers, the latter could take nearly $60 \mathrm{wt} \%$ more water but had the same volume swelling ratio of $47 \%$ as that of BPSH40. This could be attributed to the supramolecular interlocking and possible chain threading interactions between iptycene moieties, in addition to their strong $\pi-\pi$ stacking interaction, which effectively suppress the water swelling by transferring strain from one polymer chain to another (Tsui et al., 2007; Gong et al., 2011; Aboki et al., 2018). Moreover, increasing the iptycene molar content in the polymer backbone led to further improved membrane swelling behavior. For example, compared to TRP-BP 1:2-40 membrane containing $33 \mathrm{~mol} \%$ TRP units, TRP-BP 1:1-40 membrane containing 50 mol\% TRP unit has slightly higher water uptake (70 vs. $67 \mathrm{wt} \%$ ) but much lower swelling ratio (47 vs. 59 vol\%). This observation further supports the conclusion that iptycene units are instrumental in suppressing excessive water swelling in ionic polymers.

The trend became more complicated in copolymers involving pentiptycene units and very high sulfonation degree. Despite of the possible higher free volume suggested by the lower dry polymer densities, the PENT-BP copolymers with $40 \%$ sulfonation degree didn't show high water uptake as expected. This might be ascribed to their low IEC $_{\mathrm{w}}$ values and the more hydrophobic characteristic caused by excessive $\pi-\pi$ interactions and highly bulky structures of pentiptycene units, which may block the penetration of water molecules especially at low sulfonation degree. However, the same phenomena of suppression of swelling was observed for the PENT-BP copolymers due to the aforementioned strong $\pi-\pi$ stacking and supramolecular interactions. At high sulfonation degree (50\%), all the membranes showed markedly increased water uptake and swelling ratio as Figure 2C shows. In particular, PENT-BP 1:2-50 maintained excellent water swelling management with a very high water uptake ( $99 \mathrm{wt} \%$ ) but a moderate swelling ratio of $61 \%$. The excellent water uptake and swelling resistance might be explained by the synergistic effects of high fractional free volume, strong intra- and inter-molecular interactions between pentiptycene moieties, and high polymer backbone rigidity. However, excessive swelling behavior was observed for TRPBP 1:1-50 and TRP-BP 1:2-50 copolymer membranes. It seems that when water uptake surpasses certain critical point, the absorbed water may serve as plasticizer and breaks the interchain association formed through supramolecular interlocking and chain threading, resulting excessive swelling behavior. Additionally, TRP-BP 1:1(2)-50 copolymers had relatively low molecular weights (as evidenced by their low intrinsic viscosities) and thus might fail to form stable supramolecularly interlocked structures as in other copolymers. For instance, TRP-BP 1:1-50 had the lowest intrinsic viscosity (0.42) among all the copolymers, which consequently showed the highest water uptake and swelling ratio.

\section{Oxidative Stability}

In PEMFC operation, incomplete reduction reaction along with oxygen diffusion through membrane would generate $\cdot \mathrm{OH}$ and $\cdot \mathrm{OOH}$ radicals, which are responsible for accelerating the degradation of PEM membranes (Wang and Capuano, 1998; Hübner and Roduner, 1999; Panchenko et al., 2004; Gong and Zhang, 2011). It is believed that the attack of hydroxyl radicals mainly occurs on aromatic rings, especially in the ortho position to alkyl- and alkyl ether-substituents (Hübner and Roduner, 1999). Hot Fenton's reagent $\left(80^{\circ} \mathrm{C}\right)$ is an effective tool that has been frequently used to evaluate the oxidative stability of PEMs. The oxidative stability was quantified by the residual weight percentage after soaking in hot Fenton's reagent for $1 \mathrm{~h}$ (Figure 3). It has been shown that the oxidative stability decreases as sulfonation degree increases (Liu et al., 2007) as BPSH series exhibited. At higher sulfonation degree, BPSH 50 and TRP-BP1:1(2)-50 either dissolved or broken into small pieces during the tests. This could be attributed to the open membrane structure due to excessive water uptake and swelling 

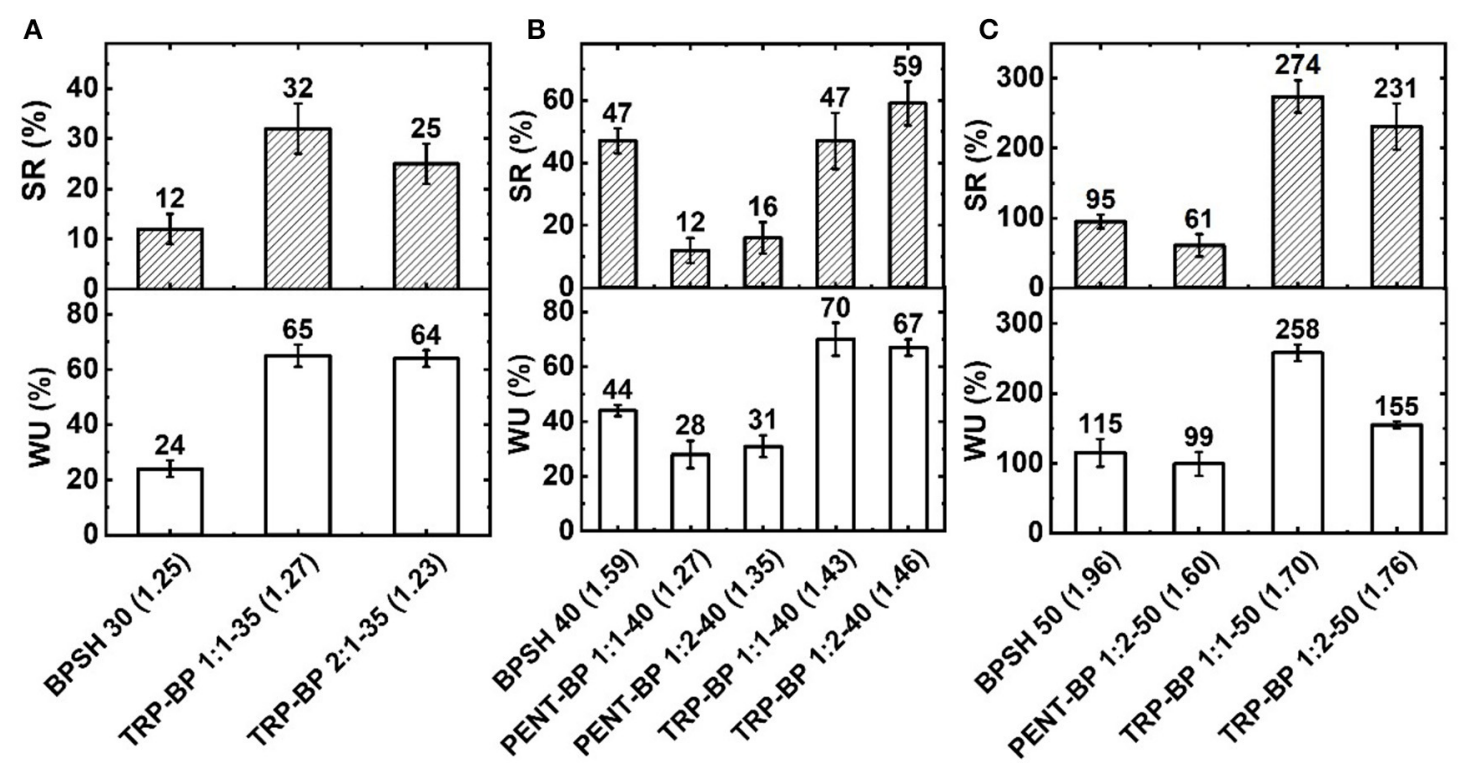

FIGURE 2 | Water uptake (WU) and swelling ratio (SR) for copolymers with (A) 30 or 35\%, (B) $40 \%$, and (C) $50 \%$ degree of sulfonation at $25^{\circ}$ C. The number in the brackets is dry weight-based $\mathrm{IEC}_{\mathrm{w}}(\mathrm{meq} / \mathrm{g})$ determined from titration method.

are more vulnerable to radical attack. It is worth noticing that PENT-BP 1:2-50 showed excellent chemical stability without detectable weight loss in the test, which might be related with the relatively low $\mathrm{IEC}_{\mathrm{w}}$ and excellent dimensional stability as a result of strong inter-chain association induced by $\pi-\pi$ stacking and supramolecular interaction. At lower sulfonation degrees, all the sulfonated random polysulfone copolymers exhibit good oxidative stabilities with residual weight over $90 \%$. In comparison, iptycene-based copolymers all exhibited higher oxidative stabilities than their BPSH counterparts. The excellent oxidative stabilities could be attributed to the strong supramolecular interlocked structures and $\pi-\pi$ interactions induced by iptycene units, which shield the polymer backbones from the radical attack.

\section{Proton Conductivity}

The in-plane proton conductivities of all the membranes were measured at varied temperatures $\left(25-80^{\circ} \mathrm{C}\right)$ in deionized (DI) water as tabulated in Table 3. As a general observation, within each copolymer series, increasing $\mathrm{IEC}_{\mathrm{W}}$ or sulfonation degree led to increased proton conductivity unless excessive water swelling [or very low $\mathrm{IEC}_{\mathrm{V}}$ (wet) values] was involved such as TRP-BP 1:1(2)-50 series. Across the three copolymer series, there are mixed trends comparing the iptycene-containing systems with the BPSH series. To examine the fundamental structure-property relationship, the proton conductivities at varied temperatures were plotted as a function of dry-weight IEC $_{\mathrm{W}}$ determined from titration method as Figure 4 shows. For BPSH and PENT-BP series, it can be seen that proton conductivities increased almost linearly with increasing IEC $_{\mathrm{W}}$ under all four temperatures, while TRP-BP series showed a different trend, particularly, for the ones with $50 \%$ sulfonation

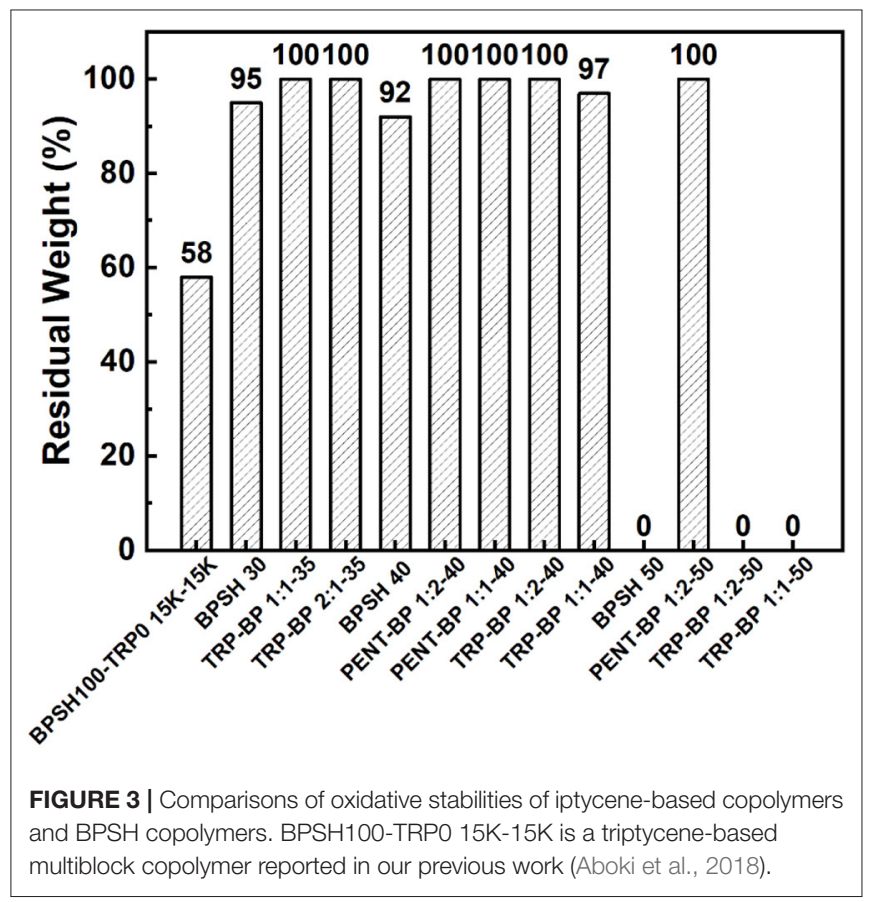

degree whose relatively low molecular weights and excessive swelling might contribute to this unusual trend. PENT-BP 1:1-40 and PENT-BP 1:2-40 showed lower conductivities than BPSH 30 with similar IEC $_{\mathrm{w}}$, consistent with the low water uptake caused by higher hydrophobicity and excessive $\pi$ $\pi$ interactions. The much higher water uptake of PENTBP 1:2-50 led to higher proton conductivities than $\mathrm{BPSH}$ 
TABLE 3 | Proton conductivity as a function of temperature and calculated activation energy $\left(E_{a}\right)$.

\begin{tabular}{|c|c|c|c|c|c|c|c|}
\hline Copolymers & $\begin{array}{c}\mathrm{IEC}_{\mathrm{w}} \text { (dry) } \\
\text { (meq/g) }\end{array}$ & $\begin{array}{l}\operatorname{IEC}_{\mathrm{v}}(\text { wet })^{\mathrm{a}} \\
\left(\mathrm{meq} / \mathrm{cm}^{3}\right)\end{array}$ & \multicolumn{4}{|c|}{ Proton conductivity $(\mathrm{mS} / \mathrm{cm})$} & $E_{\mathrm{a}}^{\mathrm{b}}(\mathrm{kJ} / \mathrm{mol})$ \\
\hline TRP-BP 2:1-35 & $1.23 \pm 0.01$ & $1.35 \pm 0.07$ & $66 \pm 2$ & $72 \pm 1$ & $75 \pm 1$ & $82 \pm 2$ & 3.41 \\
\hline TRP-BP 1:2-40 & $1.46 \pm 0.01$ & $1.22 \pm 0.06$ & $76 \pm 6$ & $83 \pm 3$ & $85 \pm 6$ & $91 \pm 8$ & 3.37 \\
\hline TRP-BP 1:1-40 & $1.43 \pm 0.01$ & $1.33 \pm 0.08$ & $70 \pm 6$ & $92 \pm 5$ & $100 \pm 3$ & $108 \pm 4$ & 7.68 \\
\hline TRP-BP 1:1-50 & $1.70 \pm 0.02$ & $0.63 \pm 0.04$ & $51 \pm 3$ & $72 \pm 2$ & $80 \pm 3$ & $83 \pm 3$ & 8.81 \\
\hline PENT-BP 1:2-40 & $1.35 \pm 0.01$ & $1.55 \pm 0.08$ & $40 \pm 4$ & $61 \pm 1$ & $71 \pm 1$ & $80 \pm 6$ & 11.4 \\
\hline PENT-BP 1:1-40 & $1.27 \pm 0.01$ & $1.49 \pm 0.06$ & $30 \pm 3$ & $49 \pm 8$ & $59 \pm 2$ & $73 \pm 4$ & 14.4 \\
\hline PENT-BP 1:2-50 & $1.60 \pm 0.01$ & $1.29 \pm 0.13$ & $88 \pm 6$ & $111 \pm 2$ & $117 \pm 7$ & $133 \pm 6$ & 6.56 \\
\hline BPSH 30 & $1.25 \pm 0.01$ & $1.53 \pm 0.05$ & $43 \pm 6$ & $59 \pm 3$ & $75 \pm 5$ & $78 \pm 3$ & 10.1 \\
\hline
\end{tabular}

${ }^{a}$ Calculated using Equation (5).

${ }^{b}$ Calculated using Equation (7).
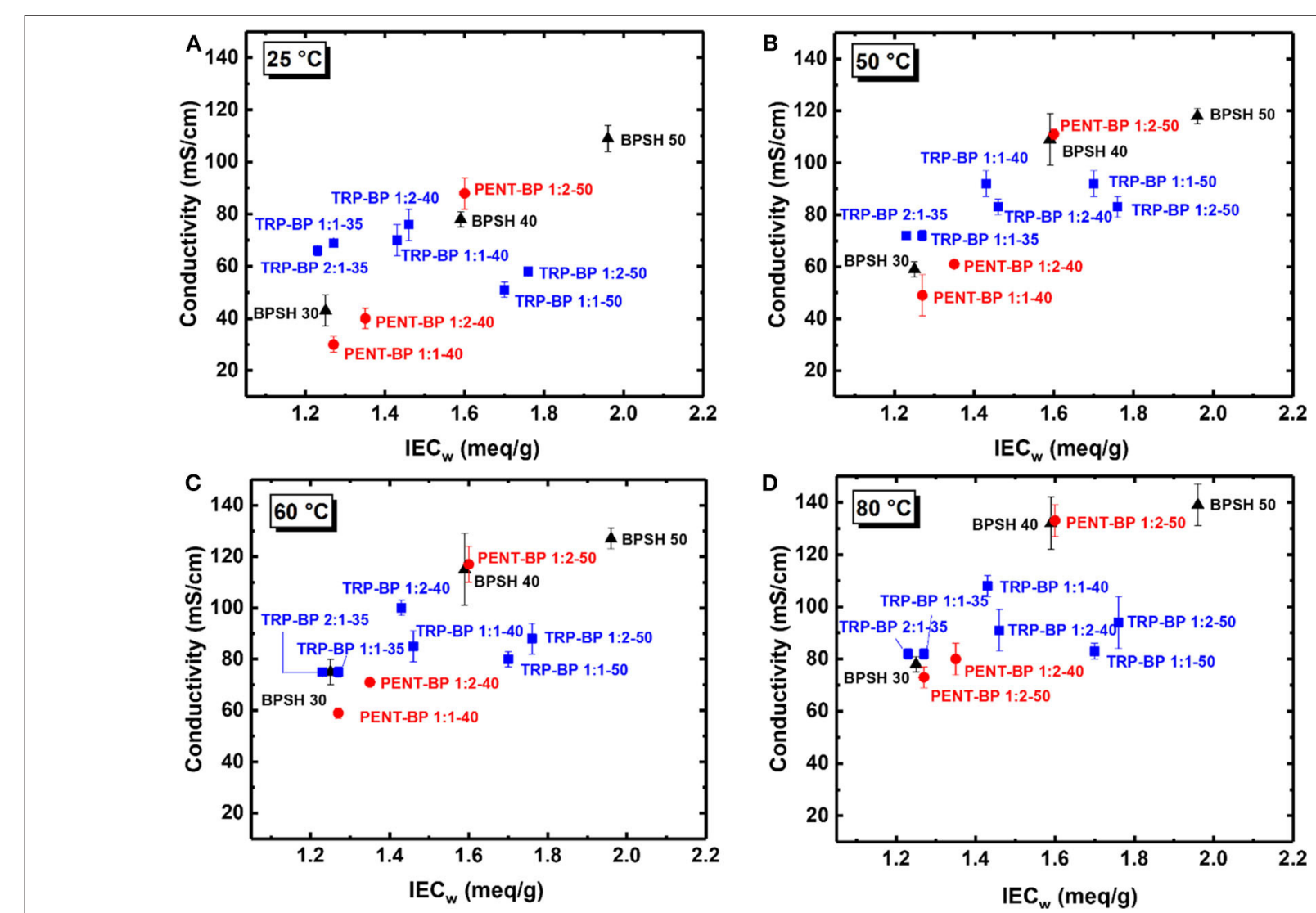

FIGURE 4 | Proton conductivities of BPSH, TRP-BP, and PENT-BP copolymer series at (A) $25^{\circ} \mathrm{C}$, (B) $50^{\circ} \mathrm{C}$, (C) $60^{\circ} \mathrm{C}$, and (D) $80^{\circ} \mathrm{C}$.

40 even they share similar dry weight IEC $_{\mathrm{w}}(1.60 \mathrm{meq} / \mathrm{sg}$ and $1.59 \mathrm{meq} / \mathrm{g}$, respectively). Interestingly, PENT-BP 1:2-50 with much higher water uptake than BPSH 40 (99 vs. 44\%) showed much improved conductivities at $25^{\circ} \mathrm{C}$ (88 vs. 78 $\mathrm{mS} / \mathrm{cm}$ ) but similar conductivities of $\sim 132 \mathrm{mS} / \mathrm{cm}$ at higher temperatures. This phenomenon could be explained by the proton transport mechanism: the translational mode gradually transits from Grotthuss mechanism to vehicle-type mechanism with increasing temperature (Kreuer, 1996). Different from the "smooth" backbone of BPSH 40, the bulky structure and pendant fused arene rings of pentiptycene units in PENT-BP series increase the pathway tortuosity that might slow down 

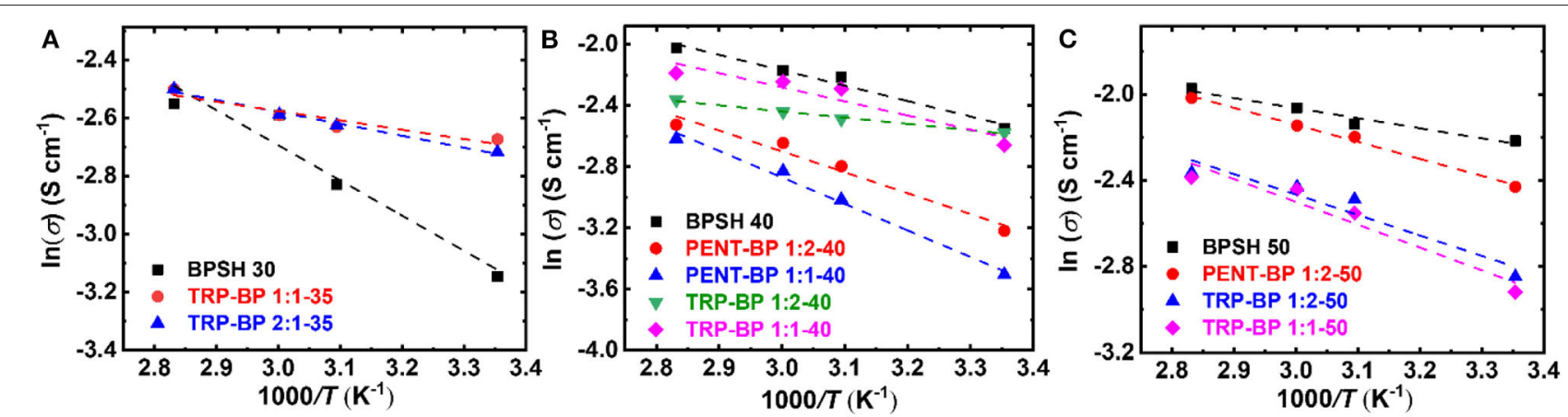

FIGURE 5 | Arrhenius plot of log conductivity vs. 1/T for copolymers with (A) 30 or 35\%, (B) 40\%, and (C) $50 \%$ degree of sulfonation.

the proton transporting vehicles (i.e., $\mathrm{H}_{3} \mathrm{O}^{+}$), compromising the conductivity increase at high temperatures.

For TRP-BP series, the situations were more complicated. TRP-BP 1:1-35 and TRP-BP 2:1-35 are more conductive at all the temperatures than BPSH 30, PENT-BP 1:1-40 and PENT-BP 1:2-40, which had similar $\mathrm{IEC}_{\mathrm{W}}$ values. For example, at $25^{\circ} \mathrm{C}$, TRP-BP 2:1-35 and TRP-BP 1:1-35 have proton conductivities of 66 and $69 \mathrm{mS} / \mathrm{cm}$, respectively, much higher than BPSH $30(43 \mathrm{mS} / \mathrm{cm})$, PENT-BP 1:1-40 $(30 \mathrm{mS} / \mathrm{cm})$, and PENT-BP 1:2-40 $(40 \mathrm{mS} / \mathrm{cm})$. The excellent proton conductivities of TRP$\mathrm{BP}$ series even with low IEC $_{\mathrm{w}}$ values are consistent with their high water uptake of $\sim 65 \%$ (Figure 2). As for the effect of iptycene content, the proton conductivities of TRP-BP 1:1$40\left(I E C_{w}=1.43 \mathrm{meq} / \mathrm{g}\right)$ surpassed TRP-BP 1:2-40 $(1.46 \mathrm{meq} / \mathrm{g})$ at $50^{\circ} \mathrm{C}$ and finally reached $108 \mathrm{mS} / \mathrm{cm}$ at $80^{\circ} \mathrm{C}$ (cf. Table 3 or Figure 4), approximately $16 \%$ greater than the latter. The conductivity increase at higher temperatures is possibly due to more stable interlocked structures in the copolymer with higher iptycene content: higher percentage of triptycene units might retain the connectivity of ionic domains facilitating the vehicletype proton transport at high temperatures. However, TRP-BP 1:1-50 and TRP-BP 1:2-50 ionomers with high IEC $_{\mathrm{W}}$ values suffered cliff-like drops in proton conductivities, consistent with the excessive water uptake and water-swollen behaviors, where the ion concentration is too dilute to form continuous conduction. As such, TRP-BP 1:1-50 and TRP-BP 1:2-50 with very low volume-based IEC $_{\mathrm{V}}($ wet $)$ values of $\sim 0.7 \mathrm{meq} / \mathrm{cm}^{3}$ exhibited lower conductivities than BPSH 40, PENT-BP 1:250 , and BPSH 50, which have much higher $\operatorname{IEC}_{\mathrm{V}}$ (wet) values $\left(\geq 1.29 \mathrm{meq} / \mathrm{cm}^{3}\right)$. As mentioned earlier, the excessive waterswollen stress may override the $\pi-\pi$ interactions and deteriorate the interlocked structures from triptycene units.

The relationship between the proton conductivity $(\sigma)$ and temperature $(T)$ was well-expressed by the Arrhenius equation as follows (Lee et al., 2005),

$$
\ln \sigma=\ln \sigma_{0}-\frac{E_{a}}{R T}
$$

where $\sigma_{0}$ is the frequency factor, $R$ is gas constant (8.314 $\mathrm{J} \mathrm{mol}^{-1} \mathrm{~K}^{-1}$ ), and $T$ is absolute temperature $(\mathrm{K})$. The activation energy $\left(E_{a}\right)$ was calculated from the slope of linear fit of $\ln \sigma$ vs. $1 / T$ as Figure 5 shows and the calculated values were tabulated in Table 3 . It should be noted that the activation energy values could be affected by multiple non-structure related factors such as film-casting conditions, testing method, etc. Although some samples tested here didn't rigorously follow the Arrhenius behavior (such as BPSH 30), most copolymers show rather linear correlation between $\ln \sigma$ and $1 / T$ with linearity approaching unity. Generally, a high activation energy value means proton conductivity is more sensitive to temperature change. As demonstrated in previously studies (Kim et al., 2003), the activation energy of BPSH series decreased as sulfonation degree increased due to the formation of continuous ionic domains (cf. Table 3). For PENT-BP series, the activation energy is higher than BPSH at equivalent sulfonation degree. For example, the activation energy of PENT-BP 1:1-40 (14.39 kJ/mol) is $\sim 27$ and $\sim 72 \%$ higher than PENT-BP 1:2-40 and BPSH 40. This phenomenon could be attributed to that the dynamic ion transport gradually outweighs the excessive $\pi-\pi$ interactions as temperature increases. As such, the proton conductivity of PENT-BP changes more rapidly with temperatures. For TRP-BP series, there is no obvious trend of activation energy as observed in PENT-BP and BPSH series.

\section{CONCLUSION}

Disulfonated iptycene-based poly(arylene ether sulfone) random copolymers, i.e., TRP-BP and PENT-BP, were synthesized via direct copolymerization of disulfonated monomer. The sulfonation degree and iptycene contents were systematically varied to investigate the effects of intrinsic free volume and IEC on proton exchange membrane performance. Due to the combined effects of high free volume, supramolecularly interlocked structure, and strong $\pi-\pi$ interaction associated with triptycene moieties, TRP-BP copolymers showed high water uptake with low swelling ratio as compared to $\mathrm{BPSH}$ series. Correspondingly, they exhibited much higher proton conductivities from 25 to $80^{\circ} \mathrm{C}$ than $\mathrm{BPSH}$ counterparts with similar IEC $_{\mathrm{W}}$ values. However, with even higher intrinsic free volume, pentiptycene-based PENT-BP series didn't show much improved proton conductivities at low degree of sulfonation, possibly due to their higher hydrophobicity (evidenced by low 
water uptake and swelling ratio) that compromises IEC and thus proton conductivity. For PENT-BP 1:2-50, its high sulfonation degree might overcome the hydrophobic characteristic, resulting in high water uptake, good dimensional stability as well as high conductivity. The TRP-BP and PENT-BP copolymer membranes exhibited much improved oxidative stability after $1 \mathrm{~h}$ hot Fenton's reagent treatment than BPSH series, which could be attributed to the strong supramolecular interlocked structures and $\pi-\pi$ interactions induced by iptycene units, which shield the polymer backbones from the attack of $\cdot \mathrm{OH}$ and $\cdot \mathrm{OOH}$ radicals.

\section{DATA AVAILABILITY STATEMENT}

All datasets presented in this study are included in the article/Supplementary Material.

\section{AUTHOR CONTRIBUTIONS}

TW, JA, and RG conceived the idea and designed the experiments. TW, TL, and JA synthesized the membranes. TW performed most of the characterization and measurement. TW and RG analyzed the data and wrote the report. All authors read and approved the final manuscript.

\section{ACKNOWLEDGMENTS}

The authors thank Professor Ryan Roeder and Mr. Connor Evans at the University of Notre Dame for their help in mechanical property tests. Professor Jennifer Schaefer and Miss Laura Merrill are acknowledged for their assistance in proton conductivity measurements. Center for Environmental Science and Technology (CEST) at Notre Dame is acknowledged for the use of some equipment. RG acknowledges the support from the Division of Chemical Sciences, Biosciences, and Geosciences, Office of Basic Energy Sciences of the U.S. Department of Energy (DOE), under Award no. DE-SC0019024.

\section{SUPPLEMENTARY MATERIAL}

The Supplementary Material for this article can be found online at: https://www.frontiersin.org/articles/10.3389/fchem. 2020.00674/full\#supplementary-material

\section{REFERENCES}

Aboki, J., Jing, B., Luo, S., Zhu, Y., Zhu, L., and Guo, R. (2018). Highly proton conducting polyelectrolyte membranes with unusual water swelling behavior based on triptycene-containing poly(arylene ether sulfone) multiblock copolymers. ACS Appl. Mater. Interfaces 10, 1173-1186. doi: $10.1021 /$ acsami.7b13542

Ahn, M.-K., Lee, B., Jang, J., Min, C.-M., Lee, S.-B., Pak, C., et al. (2018). Facile preparation of blend proton exchange membranes with highly sulfonated poly(arylene ether) and poly(arylene ether sulfone) bearing dense triazoles. J. Memb. Sci. 560, 58-66. doi: 10.1016/j.memsci.2018.05.011

Assumma, L., Nguyen, H.-D., Iojoiu, C., Lyonnard, S., Mercier, R., and Espuche, E. (2015). Effects of block length and membrane processing conditions on the morphology and properties of perfluorosulfonated poly(arylene ether sulfone) multiblock copolymer membranes for PEMFC. ACS Appl. Mater. Interfaces 7, 13808-13820. doi: 10.1021/acsami.5b01835

Bi, H., Wang, J., Chen, S., Hu, Z., Gao, Z., Wang, L., et al. (2010). Preparation and properties of cross-linked sulfonated poly(arylene ether sulfone)/sulfonated polyimide blend membranes for fuel cell application. J. Memb. Sci. 350, 109-116. doi: 10.1016/j.memsci.2009.12.017

Chu, S., and Majumdar, A. (2012). Opportunities and challenges for a sustainable energy future. Nature 488, 294-303. doi: 10.1038/nature11475

Dincer, I. (2000). Renewable energy and sustainable development: a crucial review. Renew. Sustain. Energy Rev. 4, 157-175. doi: 10.1016/S1364-0321(99)00011-8

Genova-Dimitrova, P., Baradie, B., Foscallo, D., Poinsignon, C., and Sanchez, J. (2001). Ionomeric membranes for proton exchange membrane fuel cell (PEMFC): sulfonated polysulfone associated with phosphatoantimonic acid. J. Memb. Sci. 185, 59-71. doi: 10.1016/S0376-7388(00)00634-7

Ghassemi, H., and McGrath, J. E. (2004). Synthesis and properties of new sulfonated poly(p-phenylene) derivatives for proton exchange membranes. I. Polymer 45, 5847-5854. doi: 10.1016/j.polymer.2004.06.021

Gong, F., Mao, H., Zhang, Y., Zhang, S., and Xing, W. (2011). Synthesis of highly sulfonated poly(arylene ether sulfone)s with sulfonated triptycene pendants for proton exchange membranes. Polymer 52, 1738-1747. doi: $10.1016 /$ j.polymer.2011.02.033

Gong, F., and Zhang, S. (2011). Synthesis of poly(arylene ether sulfone)s with locally and densely sulfonated pentiptycene pendants as highly conductive polymer electrolyte membranes. J. Power Sources 196, 9876-9883. doi: 10.1016/j.jpowsour.2011.08.028
Harrison, W. L., Hickner, M. A., Kim, Y. S., and McGrath, J. E. (2005). Poly(arylene ether sulfone) copolymers and related systems from disulfonated monomer building blocks: synthesis, characterization, and performance-a topical review. Fuel Cells 5, 201-212. doi: 10.1002/fuce.200400084

Hickner, M. A., Ghassemi, H., Kim, Y. S., Einsla, B. R., and McGrath, J. E. (2004). Alternative polymer systems for proton exchange membranes (PEMs). Chem. Rev. 104, 4587-4612. doi: 10.1021/cr020711a

Hübner, G., and Roduner, E. (1999). EPR investigation of HO/radical initiated degradation reactions of sulfonated aromatics as model compounds for fuel cell proton conducting membranes. J. Mater. Chem. 9, 409-418. doi: $10.1039 / \mathrm{a} 807129 \mathrm{~b}$

Kim, Y. S., Hickner, M. A., Dong, L., Pivovar, B. S., and McGrath, J. E. (2004). Sulfonated poly(arylene ether sulfone) copolymer proton exchange membranes: composition and morphology effects on the methanol permeability. J. Memb. Sci. 243, 317-326. doi: 10.1016/j.memsci.2004.06.035

Kim, Y. S., Wang, F., Hickner, M., Mccartney, S., Hong, Y. T., Harrison, W., et al. (2003). Effect of acidification treatment and morphological stability of sulfonated poly(arylene ether sulfone) copolymer proton-exchange membranes for fuel-cell use above $100^{\circ}$ C. J. Polym. Sci. Part B Polym. Phys. 41, 2816-2828. doi: 10.1002/polb.10496

Kreuer, K. D. (1996). Proton conductivity: materials and applications. Chem. Mater. 8, 610-641. doi: 10.1021/cm950192a

Lee, C. H., Park, H. B., Lee, Y. M., and Lee, R. D. (2005). Importance of proton conductivity measurement in polymer electrolyte membrane for fuel cell application. Ind. Eng. Chem. Res. 44, 7617-7626. doi: 10.1021/ie0501172

Lee, H. S., Roy, A., Lane, O., Dunn, S., and McGrath, J. E. (2008). Hydrophilichydrophobic multiblock copolymers based on poly(arylene ether sulfone) via low-temperature coupling reactions for proton exchange membrane fuel cells. Polymer 49, 715-723. doi: 10.1016/j.polymer.2007.12.023

Li, N., Lee, S. Y., Liu, Y.-L., Lee, Y. M., and Guiver, M. D. (2012). A new class of highly-conducting polymer electrolyte membranes: aromatic ABA triblock copolymers. Energy Environ. Sci. 5, 5346-5355. doi: 10.1039/C1EE 02556B

Liang, X., Zhang, F., Feng, W., Zou, X., Zhao, C., Na, H., et al. (2013). From metal-organic framework (MOF) to MOF-polymer composite membrane: enhancement of low-humidity proton conductivity. Chem. Sci. 4, 983-992. doi: $10.1039 / \mathrm{C} 2 \mathrm{SC} 21927 \mathrm{~A}$

Liu, B., Robertson, G. P., Kim, D. S., Guiver, M. D., Hu, W., and Jiang, Z. (2007). Aromatic poly(ether ketone)s with pendant sulfonic acid phenyl groups 
prepared by a mild sulfonation method for proton exchange membranes. Macromolecules 40, 1934-1944. doi: 10.1021/ma061705

Luo, H., Aboki, J., Ji, Y., Guo, R., and Geise, G. M. (2018). Water and salt transport properties of triptycene-containing sulfonated polysulfone materials for desalination membrane applications. ACS Appl. Mater. Interfaces 10, 4102-4112. doi: 10.1021/acsami.7b17225

Luo, S., Liu, Q., Zhang, B., Wiegand, J. R., Freeman, B. D., and Guo, R. (2015). Pentiptycene-based polyimides with hierarchically controlled molecular cavity architecture for efficient membrane gas separation. J. Memb. Sci. 480, 20-30. doi: 10.1016/j.memsci.2015.01.043

Matsumoto, K., Higashihara, T., and Ueda, M. (2008). Star-shaped sulfonated block copoly(ether ketone)s as proton exchange membranes. Macromolecules 41, 7560-7565. doi: 10.1021/ma8015163

Miyatake, K., Yasuda, T., Hirai, M., Nanasawa, M., and Watanabe, M. (2007). Synthesis and properties of a polyimide containing pendant sulfophenoxypropoxy groups. J. Polym. Sci. Part A Polym. Chem. 45, 157-163. doi: $10.1002 /$ pola.21816

Moh, L. C. H., Goods, J. B., Kim, Y., and Swager, T. M. (2018). Free volume enhanced proton exchange membranes from sulfonated triptycene poly(ether ketone). J. Memb. Sci. 549, 236-243. doi: 10.1016/j.memsci.2017.11.041

Omer, A. M. (2008). Energy, environment and sustainable development. Renew. Sustain. Energy Rev. 12, 2265-2300. doi: 10.1016/j.rser.2007.05.001

Panchenko, A., Dilger, H., Möller, E., Sixt, T., and Roduner, E. (2004). In situ EPR investigation of polymer electrolyte membrane degradation in fuel cell applications. J. Power Sources 127, 325-330. doi: 10.1016/j.jpowsour.2003.09.047

Peighambardoust, S. J., Rowshanzamir, S., and Amjadi, M. (2010). Review of the proton exchange membranes for fuel cell applications. Int. J. Hydrogen Energy 35, 9349-9384. doi: 10.1016/j.ijhydene.2010.05.017

Smitha, B., Sridhar, S., and Khan, A. A. (2005). Solid polymer electrolyte membranes for fuel cell applications-a review. J. Memb. Sci. 259, 10-26. doi: 10.1016/j.memsci.2005.01.035

Tsui, N. T., Torun, L., Pate, B. D., Paraskos, A. J., Swager, T. M., and Thomas, E. L. (2007). Molecular barbed wire: threading and interlocking for the mechanical reinforcement of polymers. Adv. Funct. Mater. 17, 1595-1602. doi: 10.1002/adfm.200600707

Wang, C., Shin, D. W., Lee, S. Y., Kang, N. R., Lee, Y. M., and Guiver, M. D. (2012). Poly(arylene ether sulfone) proton exchange membranes with flexible acid side chains. J. Memb. Sci. 405-406, 68-78. doi: 10.1016/j.memsci.2012. 02.045

Wang, F., Hickner, M., Ji, Q., Harrison, W., Mecham, J., Zawodzinski, T. A., et al. (2001). Synthesis of highly sulfonated poly(arylene ether sulfone) random(statistical) copolymers via direct polymerization. Macromol. Symp. 175, 387-396. doi: 10.1002/1521-3900(200110)175:1<387::AID-MASY387>3.0.CO;2-1
Wang, F., Hickner, M., Kim, Y. S., Zawodzinski, T. A., and McGrath, J. E. (2002). Direct polymerization of sulfonated poly(arylene ether sulfone) random (statistical) copolymers: candidates for new proton exchange membranes. J. Memb. Sci. 197, 231-242. doi: 10.1016/S0376-7388(01)00620-2

Wang, H., and Capuano, A. C. (1998). Behavior of raipore radiation-grafted polymer membranes in $\mathrm{H}_{2} / \mathrm{O}_{2}$ fuel cells. J. Electrochem. Soc. 145:780. doi: $10.1149 / 1.1838345$

Wang, L., Deng, N., Wang, G., Ju, J., Cheng, B., and Kang, W. (2019). Constructing amino-functionalized flower-like metal-organic framework nanofibers in sulfonated poly(ether sulfone) proton exchange membrane for simultaneously enhancing interface compatibility and proton conduction. ACS Appl. Mater. Interfaces 11, 39979-39990. doi: 10.1021/acsami.9b13496

Wang, Y., Chen, K. S., Mishler, J., Chan, S., and Cordobes, X. (2011) A review of polymer electrolyte membrane fuel cells : technology, applications, and needs on fundamental research. Appl. Energy 88, 981-1007. doi: 10.1016/j.apenergy.2010.09.030

Wiegand, J. R., Smith, Z. P., Liu, Q., Patterson, C. T., Freeman, B. D., and Guo, R. (2014). Synthesis and characterization of triptycene-based polyimides with tunable high fractional free volume for gas separation membranes. J. Mater. Chem. A 2, 13309-13320. doi: 10.1039/C4TA02303J

Yasuda, H., Lamaze, C. E., and Ikenberry, L. D. (1969). Permeability of solutes through hydrogel polymer membranes. Makromol. Chem 118, 19-35. doi: 10.1002/macp.1968.021180102

Yue, B., Zeng, G., Zhang, Y., Tao, S., Zhang, X., and Yan, L. (2017). Improved performance of acid-base composite of phosphonic acid functionalized polysulfone and triazolyl functionalized polysulfone for PEM fuel cells. Solid State Ionics 300, 10-17. doi: 10.1016/j.ssi.2016.11.011

Zhao, C., Xue, J., Ran, F., and Sun, S. (2013). Modification of polyethersulfone membranes-a review of methods. Prog. Mater. Sci. 58, 76-150. doi: 10.1016/j.pmatsci.2012.07.002

Zhou, L., Zhu, J., Lin, M., Xu, J., Xie, Z., and Chen, D. (2020). Tetraalkylsulfonate functionalized poly(aryl ether) membranes with nanosized hydrophilic channels for efficient proton conduction. J. Energy Chem. 40, 57-64. doi: 10.1016/j.jechem.2019.02.013

Conflict of Interest: The authors declare that the research was conducted in the absence of any commercial or financial relationships that could be construed as a potential conflict of interest.

Copyright (c) 2020 Wang, Li, Aboki and Guo. This is an open-access article distributed under the terms of the Creative Commons Attribution License (CC BY). The use, distribution or reproduction in other forums is permitted, provided the original author(s) and the copyright owner(s) are credited and that the original publication in this journal is cited, in accordance with accepted academic practice. No use, distribution or reproduction is permitted which does not comply with these terms. 